\title{
Allopolyploidy and Aneuploidy in the Genus Nicotiana
}

\author{
U. Subhashini \\ Central Tobacco Research Institute, Rajahmundry, India
}

Received February 22, 1975

Interspecific hybridization between the species Nicotiana umbratica and Nicotiana glutinosa followed by colchiploidy resulted in allopolyploid $(2 \mathrm{n}=70)$ aneuploids $(2 n=66,68)$ and hyperploid $(2 n=72)$ of the above hybrid. These polyploids are stable in morphological and cytological features. However abnormalities such as apical bud suppression and heteromorphic pollen were observed from $\mathrm{C}_{3}$ generation irrespective of its chromosomal complement. The above stable polyploids supports Goodspeed's postulate (1954).

\section{Material and methods}

Colchicine treatment was successful in the $\mathrm{F}_{1}$ hybrid of $N$. umbratica $\times N$. glutinosa. Cytological screening was made as per Swaminathan et al. (1954).

\section{Observations}

The colchicine treated plants revealed the characteristic symptoms of the drug such as stunted growth, thickened leaves, delayed flowering, dark pink flowers with good pollen fertility and capsule setting. General morphological characters were recorded from 40 plants in each generation $\left(C_{2}\right.$ to $\left.C_{5}\right)$ and tabulated in Table 1 . The progenies in general were uniform for morphological characters (Figs. 1 and 2) and more vigorous in growth. Pollen fertility and capsule setting were good. In the $C_{3}$ generation a few abnormalities such as apical bud suppression and heteromorphic pollen were recorded (Subhashini 1974).

Cytological screening of the colchiploid plants revealed a complement of $2 \mathrm{n}=$ $67,68,70$. Detail studies were made in all the progenies of the colchiploids and here only the progeny of $2 n=67$ is given. At diakinesis (Fig. 3) the configuration was $33^{\mathrm{II}}+1^{\mathrm{I}}$. There was a tendency for early separation of the rod bivalents at diakinesis itself. Post metaphase I irregularities of the aneuploid 67 are tabulated below.

\begin{tabular}{cccccc}
\hline $\begin{array}{c}\text { Chromosome } \\
\text { number }\end{array}$ & $\begin{array}{c}\text { Configuration } \\
\text { at diakinesis }\end{array}$ & $\begin{array}{c}\text { Configuration } \\
\text { at metaphase I }\end{array}$ & Anaphase I & Anaphase II & $\begin{array}{c}\text { Pollen } \\
\text { fertility }\end{array}$ \\
\hline $2 \mathrm{n}=67$ & $33^{\mathrm{II}}+1^{\mathrm{I}}$ & $32^{\mathrm{Ir}}+3^{\mathrm{r}}$ & $\begin{array}{l}\text { Delayed and } \\
\text { unequal } \\
\text { distribution } \\
\text { and laggards }\end{array}$ & $\begin{array}{l}\text { Irregular } \\
\text { with } \\
\text { laggards }\end{array}$ & $90 \%$ \\
\hline
\end{tabular}

In spite of the above irregularities the pollen fertility was as high as $90 \%$. Germination of the pollen grains on the stigmatic surface as well as on the artificial 
Table 1. Morphological description of N. umbratica, $N$. glutinosa and the colchiploid

\begin{tabular}{|c|c|c|c|c|}
\hline $\begin{array}{l}\text { Parent or hybrid } \\
\text { character }\end{array}$ & N. umbratica & $N$. glutinosa & Colchiploids & $C_{3}$ generation \\
\hline $\begin{array}{l}\text { Chromosome } \\
\text { number } 2 n=\end{array}$ & 46 & 24 & $67-70$ & \\
\hline $\begin{array}{l}\text { General } \\
\text { appearance }\end{array}$ & & & $\begin{array}{l}\text { Mostly intermedi- } \\
\text { ate in some re- } \\
\text { spects resembled } \\
N . \text { glutinosa }\end{array}$ & As the $C_{1}$ plants \\
\hline $\begin{array}{l}\text { Plant height at } \\
\text { flowering }\end{array}$ & about $10.5 \mathrm{~cm}$ & about $32.0 \mathrm{~cm}$ & about $38.0 \mathrm{~cm}$ & about $30.0 \mathrm{~cm}$ \\
\hline Stem & $\begin{array}{l}\text { Main axis suppress- } \\
\text { ed profuse branch- } \\
\text { es from the axils. } \\
\text { Color of the } \\
\text { branches light } \\
\text { green }\end{array}$ & $\begin{array}{l}\text { Main axis thick } \\
\text { round, elongated } \\
\text { color dark green } \\
\text { with stiff axil- } \\
\text { lary branches }\end{array}$ & $\begin{array}{l}\text { As in } N \text {. glutinosa } \\
\text { with violet tinge } \\
\text { on the main axis }\end{array}$ & As the $C_{1}$ \\
\hline $\begin{array}{l}\text { Leaf color } \\
\text { texture } \\
\text { margin }\end{array}$ & $\begin{array}{l}\text { light green } \\
\text { herbaceous } \\
\text { undulate }\end{array}$ & $\begin{array}{l}\text { dark green } \\
\text { coriaceous } \\
\text { entire and leaf } \\
\text { tip twisted to- } \\
\text { wards main axis }\end{array}$ & $\begin{array}{l}\text { light green } \\
\text { coriaceous } \\
\text { undulate and leaf } \\
\text { tip as in } N . \\
\text { glutinosa }\end{array}$ & $\begin{array}{l}\text { light green } \\
\text { coriaceous } \\
\text { As the } \mathrm{C}_{1}\end{array}$ \\
\hline $\begin{array}{l}\text { Number of days } \\
\text { for flowering }\end{array}$ & 90 & 65 & 68 & 83 \\
\hline Flower color & greenish white & $\begin{array}{l}\text { yellowish light } \\
\text { red }\end{array}$ & greenish light pink & As the $C_{1}$ \\
\hline tube & $\begin{array}{l}\text { tube throat con- } \\
\text { stricted on both } \\
\text { sides }\end{array}$ & $\begin{array}{l}\text { bell shaped } \\
\text { throat }\end{array}$ & bloated throat & \\
\hline length & about $5.20 \mathrm{~cm}$ & $2.9 \mathrm{~cm}$ & Range 3.3 to $4.3 \mathrm{~cm}$ & As the $C_{1}$ \\
\hline spread & about $2.20 \mathrm{~cm}$ & $1.9 \mathrm{~cm}$ & Range 2.0 to $2.9 \mathrm{~cm}$ & \\
\hline $\begin{array}{l}\text { stamens } \\
\text { PF }\end{array}$ & $\begin{array}{l}\text { subdidynamous } \\
\text { and epipetalous } \\
98 \%\end{array}$ & $\begin{array}{l}\text { subdidynamous } \\
\text { and free } 98 \%\end{array}$ & $\begin{array}{l}\text { half epipetalous } \\
80-90 \% \text { and } \\
\text { subdidynamous }\end{array}$ & $\begin{array}{l}95 \% \text { hetero- } \\
\text { morphic }\end{array}$ \\
\hline Gynoecium & normal & normal & normal & Heterostyle. \\
\hline $\begin{array}{l}\text { Number of } \\
\text { seeds/capsule }\end{array}$ & More than 300 & More than 1000 & About 115 & $115 \pm 10$ \\
\hline
\end{tabular}
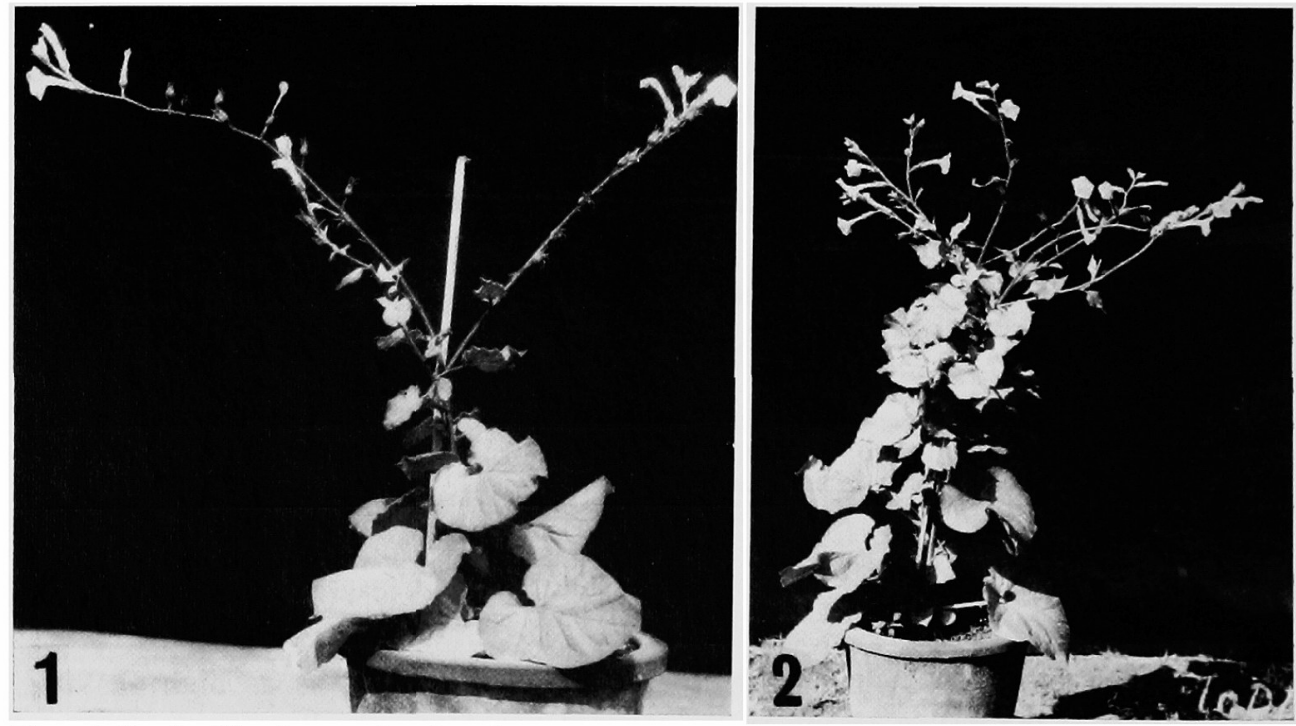

Figs. 1-2. 1, Nicotiana umbratica-glutinosa $(2 \mathrm{n}=69) . \quad 2$, Nicotiana umbratica-glutinosa $(2 \mathrm{n}=68)$. 
media was good.

There was a wide spectrum of variation at the $\mathrm{C}_{2}$ level from the aneuploid $2 n=67$ (Pedigree Chart). The different chromosomal types encountered were 62, $65,68,69$ and 70 of which the progenies of 62,65 and 70 are given in detail.

\section{General trend of the different chromosomal complements in the progenies}

The amphiploid 70 had a disturbed cytological behaviour in $\mathrm{C}_{2}$ generation resulting in types 72,70 and 68 in $C_{3}$ which however bred true in $C_{4}$ and $C_{5}$. One of the amphiploids which had a chromosomal complement of $2 n=70$ showed good pollen fertility but there was no capsule setting (Pedigree chart). The aneuploid 65 exhibited irregular meiosis and segregated to 66 and 65 of which the 66 bred true. The aneuploid 62 showed irregular meiosis at $C_{3}$ level and in $C_{4}$ only the type 68 was isolated which bred true.

\section{Cytology}

$2 n=70$. A total number of 22 plants screened cytologically had a complement of $2 n=70$ (Fig. 4) as expected for the amphiploid N. umbratica glutinosa. Meiosis was irregular at diakinesis and $M_{1}$ due to the presence of univalents. The univalents showed random movement towards the poles even at $M_{1}$ stage without congregating on to the equatorial plate. Some of the irregularities observed at $A_{1}$ are given below.

Meiotic irregularities in the chromosomal type $2 n=70$

\begin{tabular}{ccccccccc} 
Total & \multicolumn{2}{c}{$\begin{array}{c}\text { A regular distribution } \\
\text { number of } \\
\text { cells analysed }\end{array}$} & \multicolumn{3}{c}{$\mathrm{A}_{1}$ irregular distribution } & \multicolumn{2}{c}{ Laggards } \\
\cline { 2 - 10 } & $35-35$ & $\%$ of cells & $39-31$ & $\%$ & $37-33$ & $\%$ & Cells & $\%$ \\
\hline 48 & 32 & 67 & 10 & 21 & 2 & 4 & 4 & 8 \\
\hline
\end{tabular}

The above irregularities resulted in unequal distribution of chromosomes (Fig. 5) in the daughter cells. Since the $A_{11}$ was normal the spore quartets that resulted always were suspected to have hyperploid and deficient microspores. Inspite of these irregularities the pollen fertility was normal, indicating that the sporads with any complement ranging from 31 to 39 were functional. One of the amphiploid of $\mathrm{C}_{2}$ showed regular meiosis having sporads with a complement of 35 and good pollen fertility, but there was no capsule setting. Cytological screening was made from the progeny of the amphiploid which exhibited meiotic irregularities and good fertility. It is quite interesting to note the progeny showed deficient alloploid $2 n=68$ (Fig. 6, 2 plants), the amphiploid $2 n=70$ (7 plants) and hyperploid with a complement of $2 n=72$ ( 1 plant). At diakinesis and $M_{1}$ perfect bivalent formation $\left(34^{\mathrm{II}}, 35^{\mathrm{II}}\right.$ and $36^{\mathrm{II}}$ ) was recorded in the above types. At $\mathrm{A}_{1}$ and $\mathrm{A}_{11}$ the separation was normal. The parent plant gave functional sporads with a complement ranging from 31 to 39 chromosomes. Random fusion of the gametes with $37-31,35-35$, and $39-33$ might have resulted in plants with a complement of 68,70 and 72 . However the other types expected from random fusion of gametes were not encountered. The above three types bred true in $C_{5}$ generation.

$2 n=65$. Two plants showed a chromosomal complement of $2 n=65$ both of which differed in its meiotic behaviour. One plant showed complete pairing with one univalent $32^{\mathrm{II}}+1^{\mathrm{I}}$ while the other had $30^{\mathrm{II}}+5^{\mathrm{I}}$ (Fig. 7). The chromosomal 

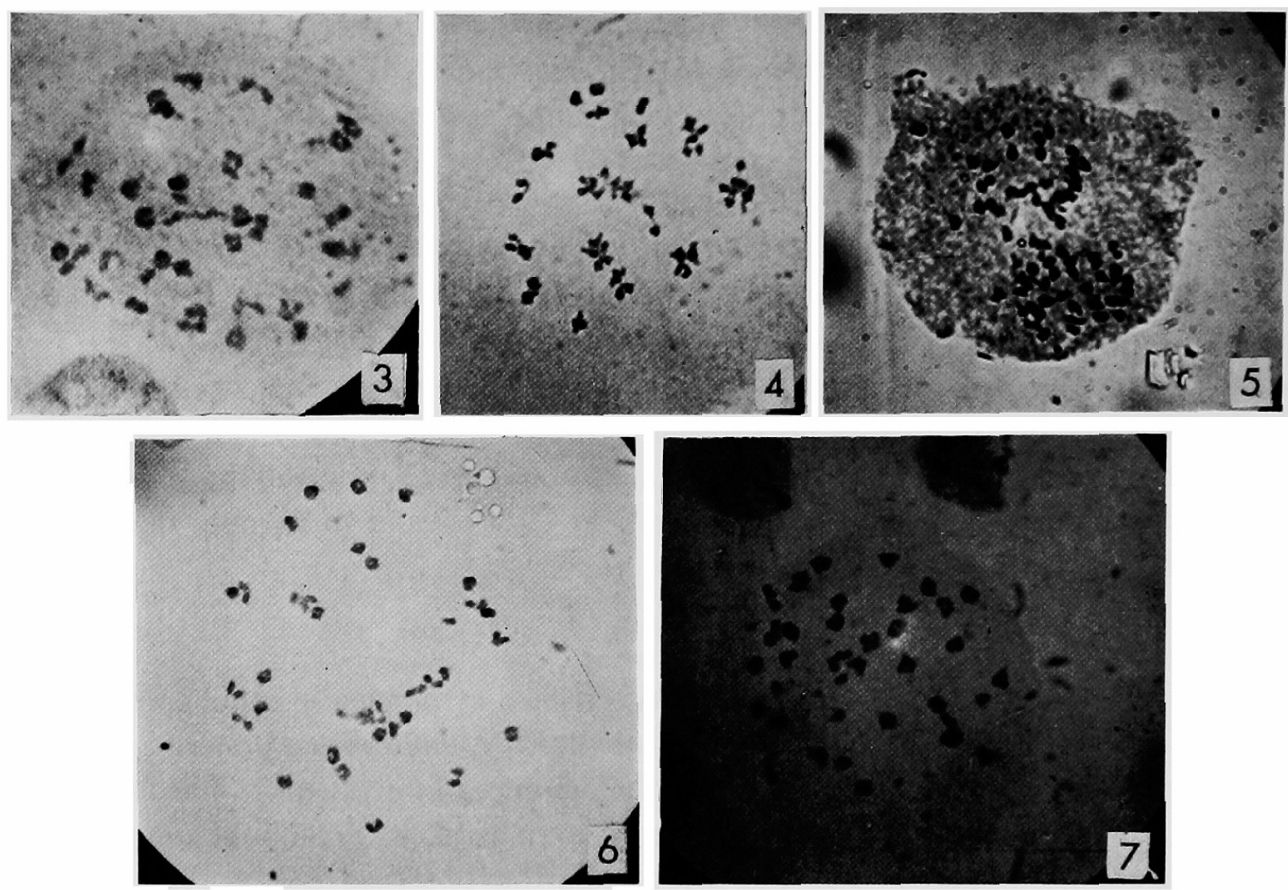

Figs. 3-7. 3, colchiploid at diakinesis $33^{\mathrm{II}}+1^{\mathrm{I}}$. 4, diakinesis showing $35^{\mathrm{II}}$. 5, unequal segregation at $A_{I} 39-31$ in the amphiploid $2 n=70.6$, diakinesis $34^{I I}$. 7 , diakinesis $30^{11}+5^{I}$.

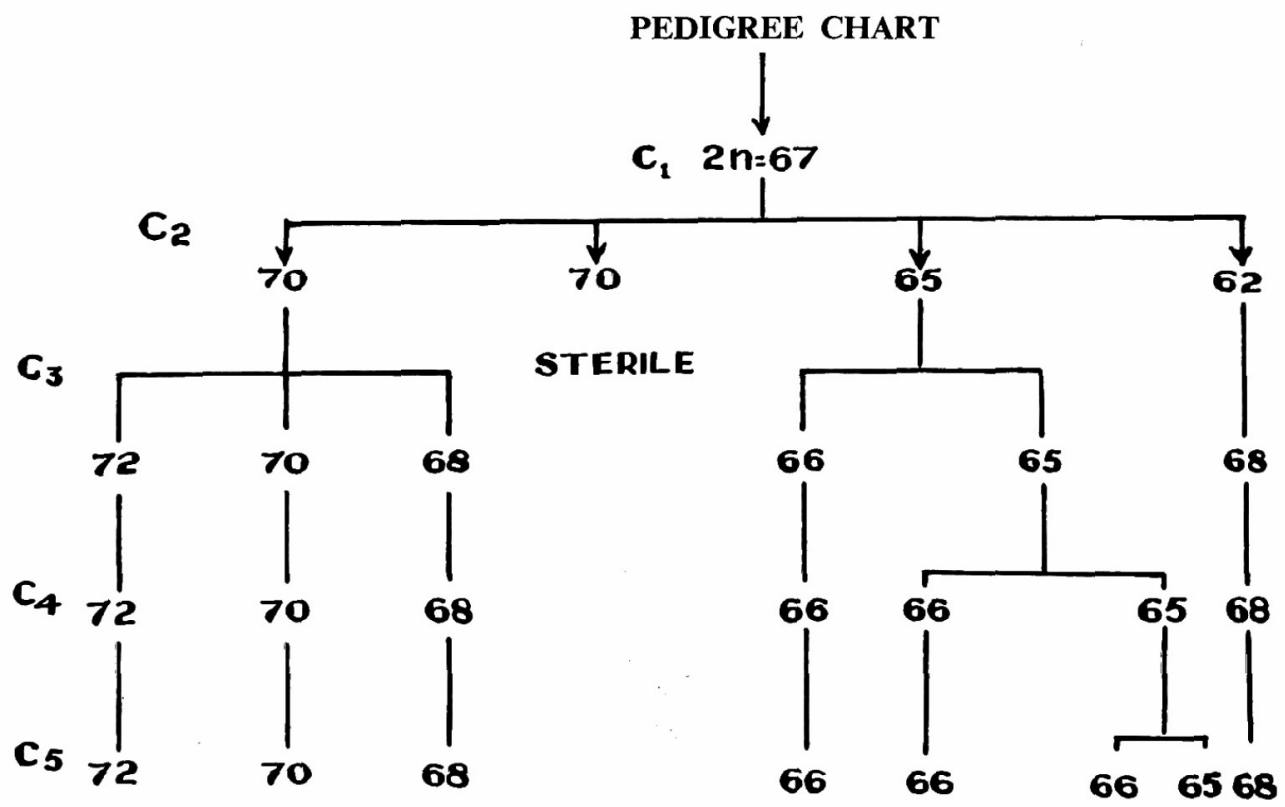

segregation at $A_{1}$ was $33-32$ in most of the cells resulting in sporads with a complement of 33 to 32 . Progeny studies in $\mathrm{C}_{3}$ were made from one of the selfed plants. In the $\mathrm{C}_{3}$ generation, two types were encountered i.e. $2 \mathrm{n}=66$ and 65 . The aneuploid 66 bred true in $C_{4}$ and $C_{5}$. The type 65 showed segregation in $C_{4}$ and $C_{5}$ of 
which only the aneuploid 66 and 65 were identified.

$2 n=62$. Only one sample in $C_{2}$ had a chromosomal complement of $2 n=62$. The configuration at $M_{1}$ was $27^{1 \mathrm{I}}+8^{\mathrm{I}}$. The irregularities noted at $A_{1}$ were delayed separation, the unusual movement of the bivalents without separation to the poles resulting in unequal segregation of chromosomes and laggards at $A_{1}$ and $A_{11}$. Inspite of these irregularities the pollen fertility was good. In the $C_{3}$ progeny only the aneuploid 68 was isolated and the parental complement was not encountered. The aneuploid $2 n=68$ exhibited regular meiosis. This type bred true in $C_{4}$ and $C_{5}$.

To sumup, the progeny studies from the aneuploid 67 of the $\mathrm{C}_{2}$ generation gave two stable aneuploids, one stable hyperploid besides the amphiploid with good fertility.

\section{Discussion}

Interspecific hybridization followed by colchiploidy resulted in unstable polyploids. Instances of cytogenetic instability in the species hybrids of Nicotiana are many. These include variation in morphology and habit during plant development (Kehr and Smith 1952), interplant and intraplant variability in chromosome number (K. V. Krishnamurthy and K. V. Satyanarayana 1962, K. V. Satyanarayana and L. Subhashini 1964). In all the above instances one of the parent species was either a member of the section suaveolentes or genuinae which have their origin from alatae. N. umbratica which was used in different crosses, is an aneuploid member of the section suaveolentes which originated from a triple complex involving the section alatae, noctiflorae and acuminatae. The members of the section suaveolentes carry in their genetic makeup the basic instability factors derived from the alatoid members. As a consequence of this, hybrids arising from species where suaveolentes members are one of the parents, usually result in instability as evidenced from the works reported above.

The partial chromosomal doubling observed in this hybrid is common in the genus Nicotiana. Smith (1959) reported aneuploids of Nicotiana by colchiploidy. He was of the opinion that loss of chromosomes can take place either with or without doubling of the whole complement. Colchicine treatment in certain plants at least has been almost as constant a method for eliminating chromosomes as for doubling them.

The aneuploids in these studies showed univalents at diakinesis and $M_{1}$ as a result of precocious separation of rod bivalents. Swaminathan and Howards (1953) came across a similar case in Solanum hybrid which was due to separation of rod bivalents and it was attributed to segmental and genetic differences. Such a mechanism may be operating in the present material resulting in the formation of univalents, which showed random segregation giving rise to gametes with different complements $(\mathrm{n} \pm 1)$. Such a case was also reported in the $\mathrm{F}_{1}$ Nicotiana hybrids of $N$. megalosiphon $(\mathrm{n}=20) \times N$. glutinosa $(\mathrm{n}=12)$ by Satyanarayana and Subhashini (1964) with a complement ranging from $2 n=31,32$ and 34 .

The amphiploid $N$. umbratica-glutinosa had a chromosome number of $2 \mathrm{n}=70$ but this similarity in possessing the same chromosome number need not necessarily 
mean their genetic makeup also would be identical $\left(\mathrm{C}_{2}\right)$. As a matter of fact each one of these exhibited dissimilar pattern in meiotic behaviour producing aneuploid and hyperploid gametes. The aneuploid gametes in the genus Nicotiana are functional as the genus had polyploid origin and the chromosome loss of one species is being compensated by the other. Thus due to the functioning of aneuploid and hyperploid gametes in the $C_{2}$ generation, a number of aneuploids and hyperploid $(2 n=72)$ were isolated. It would appear from the progeny studies of this hybrid that the aneuploid gametes had a better chance for survival rather than hyperploid gametes.

One of the amphiploids $(2 n=70)$ showed regular meiosis, resulting in good pollen fertility, but there was no capsule setting (Pedigree chart). A similar case was reported in Nicotiana hybrids (Apparao and Krishnamurthy 1963, Satyanarayana and Subhashini 1964). Clausen, Keck and Heisey (1945) were of the opinion that not every sterile hybrid is converted by polyploidy into a vigorous fertile form, probably a great majority of them are eliminated as misfit. The proper gene combination, therefore should go hand in hand with hybridization and chromosome doubling if full advantage is to be taken of allopolyploidy.

The present studies which are showing a chromosomal complement of $2 n=66$, 68,70 and 72 are stable and fertile. These stable polyploids supports Goodspeed's (1954) postulate wherein he has suggested that the future of the genus will include polyploid level above the 24 paired one.

\section{Summary}

By colchiploidy a number of unstable polyploids were obtained. The progeny of the unstable aneuploid $2 n=67$ gave a number of stable polyploids $2 n=66,68$, 70,72 in the later generations. These stable polyploids which are above the 24 paired level is a positive proof of what Goodspeed (1954) has postulated.

\section{References}

Apparao, K. and Gopinath, D. M. 1968. Colchicine induced mutations in a trispecific Nicotiana hybrid. Canadian J. Genet. and Cytol. 10 (4): 782-7.

Clausen, J., Keck, D. D. and Hiesey, W. M. 1945. Experimental studies on the nature of species. II. Plant evolution through amphiploidy and autoploidy with examples from Madiinae. Carnegie Inst. Wash. Publ. 564: 1-174.

Goodspeed, T. H. 1954. The genus Nicotiana. Chronica Botanica.

Kehr, A. and Smith, H. H. 1952. Multiple genome relationships in Nicotiana. Cornell Univ., Agr. Expt. Sta. Mem. 311: 1-19.

Krishnamurthy, K. V. and Satyanarayana, K. V. 1962. Chromosome elimination and phenotypic variability in a trispecific Nicotiana hybrid. Japan J. Genet. 37(6): 485-97.

Satyanarayana, K. V. and Subhashini, L. 1964. Interspecific hybridization and aneuploidy in the genus Nicotiana. Indian J. Genet. 24(3): 264-71.

Smith, H. H., Stevenson, H. Q. and Kehr, A.E. 1958. Limits and consequences of multiple allopolyploidy in Nicotiana. The Nucleus 1 : 205-22.

Subhashini, U. 1974. Study of the cytoplasmic effect in the interspecific cross Nicotiana umbratica B. $\times N$. glutinosa L. Euphytica 23: 289-93. 
Swaminathan, M. S., Magoon, M. L. and Mehra, K. L. 1954. A simple propionocarmine PMC smear method for plants with small chromosome. Indian J. Genet. 14: 87-8.

- and Howard, H.W. 1953. The cytology and genetics of potato (Solanum tuberosum) and related species. Biblio. Genetica 16: 1-192. 